\title{
The Localization Research on Self-Learning in College English Education
}

\author{
Yin $\mathrm{Xin}^{1}$, Ye $\mathrm{Na}^{2}$ \\ ${ }^{1}$ Department of Nursing, Hebei Women's Vocational College, Shijiazhuang \\ ${ }^{2}$ Department of Preschool Education, Hebei Women's Vocational College, Shijiazhuang \\ yinxin1016@hotmail.com
}

Keywords: Localization Research, Self-Learning, College English Education

\begin{abstract}
This paper reviews the origin of self-study, described the material basis for the existence of self-learning, and based on self-learning theory analysis the conditions which the independent learners must have. On this basis, this paper introduced the self-learning environment and quality of modern Chinese university students. It also explored positioned the self-learning in college English teaching. Finally, we proposed the self-learning mode with integration of traditional teaching.
\end{abstract}

\section{Introduction}

In recent years, as a new teaching philosophy, self-learning has become the mainstream thinking in college English teaching reform, the Ministry of Education, was listed in "College English Curriculum Requirements (Trial)", many schools take the lead in launching an independent study, research there have been more and more areas of related research, which undoubtedly played a significant role in promoting the teaching of college English. However, domestic research on autonomous learning seems a lot of research, "the prospects for the country to carry out independent study of overly optimistic." In practice, the independent study carried out appears to be a blind trend, some universities ignore weak student self-learning ability, relying on limited multimedia classrooms, in the absence of independent learning management practices, the profit-oriented, and vigorously to reduce classroom hours face to face, resulting in a waste of teaching resources, teaching effectiveness is low. Some teachers is equivalent to the self-learning, ignoring the important role of teachers led students laissez-faire, low interest in learning. Some teachers teaching a mere formality, insisting students to design autonomous learning in the classroom simply pandering to the wishes of the students while ignoring language knowledge. All this is of College English Autonomous Learning misunderstanding [1].

Well, according to the quality of our current teaching environment and college students, independent study should be how to locate in college English teaching? To what extent can the classroom using self-learning model? This article reviews the self-study of the origin, described the existence of independent learning material base, and self-learning theory, analysis of independent learner must have the condition. As a benchmark, cf. perspective as well as the quality of institutions of higher learning and the learning environment of modern university students in China, and positioning independent study in college English teaching. Finally, proposed the integration of traditional teaching of compromise self-learning mode.

\section{The Conditions of Self-learning}

Independent learning is a product of social needs and cultural, scientific and educational development. Its rise and specific social, historical, cultural and educational background is closely related to its use depends on certain material base. From the self-study the origin, we can see the emergence and development must have the material conditions and social and historical background.

From the rise of self- study to see their material conditions abroad. Independent learning from the 20th century, late 60s, early 70s adult education reform in Europe. After rapid development after 
World War II Western society, economic recovery, technological, cultural, appeared in all sectors, all organizations as the main wave of various social and recorders, multimedia, fax, e-mail, newspapers and other learning materials and advanced equipment, independent study to provide a favorable social environment and material basis. On the other hand, humanism and constructivism abandoned the behaviorist stimulus-response patterns in the field of education, psychology and linguistics caused the epoch-making change, for language teaching had a huge impact, replace the Communicative Approach Traditional grammar teaching has become the mainstream thinking of language teaching. Foreign language teaching pay attention to the idea of function-oriented and to cultivate students' communicative competence as the ultimate goal of teaching in such social and cultural background, independent study of its characteristic individualized education attracted the attention of foreign education [2].

Currently, self-learning has been widely popular in various foreign schools, especially applied to adult education, distance education and computer-assisted instruction. "Most universities in the world practice is to establish a special independent learning center, providing a fixed place for different language learning foreign language proficiency of students."

From the independent learning theory to see the conditions of self-study learner. After the 1990s, research on independent learning problems abroad more extensive, in-depth and especially in the basic issues of substance and self-learning mechanisms have made significant progress. Each theoretical schools such as Vygotsky school, operating doctrine, the phenomenon of school, school of social cognition, volition theory, information processing psychology are all made from different angles are discussed.

Zimmerman and other theorists to reveal the general characteristics of autonomous learning, and their research results are widely used and expanding in various disciplines in the field of education. In language teaching, the essence of domestic and foreign linguists also studies a foreign language self-study from a different side.

Holec on the "independent study" made the following definition: learner autonomy is the students' ability to self-manage language learning, specifically, is the ability to determine their own learning goals, identify learning content and progress, choose to study methods and techniques, monitor learning too self-assessment process and learning outcomes. He pointed out that self-learning to have two prerequisites: First learner must have the ability to manage their learning, and second, there must be such a learning institution, students can dominate in this body in their own learning.

And Benson put the learning into individual autonomy, social, psychological and political 4 different levels. "Emphasis on personal autonomy level of attention to individual learning style, emphasis on individual choice above the collective choice on the autonomy of the social hierarchy is in cooperation and interaction with others carried out and it is carried out in personal reflection and practice The importance of learner autonomy prominent psychological factors psychological level. At the same time, Benson also stressed that learners should have good psychological quality, its successes and failures responsible for learning. Autonomy on the political level refers to autonomy sex is a form of political objectives or needs service. "

In summary, the present, our students to achieve the goal of self-study, you must have the following characteristics: 1) independent learning styles, including separate cognitive strategies and meta-cognitive strategies; 2) positive learning attitude and motivation; 3 ) good learning ability, have sufficient language knowledge and skills to define and develop their own learning goals, monitor their own learning process and evaluate their own learning; and 4) collaborative and cooperative awareness and ability [3].

\section{The Location of Self-Learning in College English Teaching}

On the social environment, with respect to the Western countries, the functions of English in our society is mainly embodied in the examination, employment, promotion, rather than living an essential tool; English learning in our country is a foreign language learning, teachers and television media as learners limited understanding of learning through Western culture, lack of target language 
learners learning environment, their teacher (esp university teachers), and even a considerable part of the door has never been abroad, making it difficult for them to experience the western culture of learning; respect for teachers teach traditional Chinese culture is still a serious obstacle to learning autonomous learning. In addition, independent study in China started late, currently in institutions of higher learning in our country only at the trial stage; despite our current higher education system reform constantly, but still fall short of Western elastic credit system; the university college English Most teaching curriculum based on national unity, to implement a similar curriculum, using uniform textbooks, teacher autonomy rights has become independent learners limitations. This social context determines the presence of independent learning in our country must be limited in the form of self-learning.

In terms of hardware, though in college English teaching reform, we tried to improve the teaching environment as much as possible the introduction of multimedia network equipment, foreign language information, but, by the end of 2001 the Steering Committee of Foreign Language Teaching University 345 colleges nationwide survey shows, accounting for 70.6 percent of schools still use large-screen projection lecture, $22.8 \%$ of schools to provide staffing a machine autonomous and independent learning, remote learning classrooms and campus network only 6.6\%. Between 2005, although the rapid development of the construction of the multimedia device, carry out a comprehensive independent study from the goal is still a considerable distance. In addition, although many colleges and universities pay attention to the hardware configuration, but teachers lack knowledge of the use of computer networks and correct theoretical guidance pedagogy, unable to form and guide students to master appropriate teaching strategies independent learning. According to Dong Fuli $\mathrm{Xu}$ Wei and universities in Wuhan Region 4 related survey materials, "Only a small number of teachers sometimes or frequently used E-mail and strengthen extracurricular student exchanges, individual counseling," "up to Liucheng multimedia network teaching teachers (a) Teaching is not clear "," most teachers rarely or never assign a task requires students to extracurricular use the Internet, multimedia independently control more than three-quarters of classroom time. " At the same time, a lot of classroom teaching software development is not mature, many colleges and universities in the system, management, personnel training, teachers establish the concept of independent learning centers conditions are not met. These facts indicate the need for further independent learning in our country there are plans to be promoted.

From the learner factors, our English learners are mainly institutions of higher education students in reading and correspondence, evening and from the candidates, "according to Melton investigation early Ming Wang, the Chinese students are accustomed to independent learning, not like collective learning," they lack of social self-study required level; and Dong Wei of four universities in Wuhan on multimedia network classroom survey showed that only about 3 percent of the students to actively participate in class discussions, and better complete extracurricular collaboration learning tasks, in addition, "the vast majority of students lack critical thinking, systematic thinking and divergent thinking students learning ability, especially meta-cognitive capacity is weak." Students in the eyes of independent learning just from teachers, from classroom learning, and the current situation, many students learning English is only so-called note to remember words, read texts, doing exercise, rather than the true sense of autonomy Learn. Obviously, our modern English learners lack the necessary self-learning, independent learning style and positive attitude, they cannot independently manage their learning tasks, therefore, should be the goal of self-study college English teaching, without It should replace the traditional classroom become the main teaching tool [4].

\section{The Construction of Compromise Self-Learning Mode for College English Teaching}

First, we must fully understand and play the function of classroom teaching. Classroom learning is familiar with the process of self-study positions, this process includes short and long term goal setting, learning content settings, select study methods, cooperative learning and learning outcomes monitoring, classroom teaching to provide students demonstrate self-learning process, to help students clear learning content and learning tasks, to provide students with a platform to 
showcase their learning outcomes. This feature classroom instruction can be implemented in phases, the initial stage under the teacher's guidance by repeating this process, the students formed the habit of semi-automatic, in the next stage, group composed by the students themselves to set their own learning around the theme of the program , on display in the classroom. In advanced stages, between students, between teachers and students learning courseware co-production, improve the degree of autonomy learning. It should be noted that, due to the use of university English education at this stage is uniform syllabus, teaching materials, teaching content are unified series, which naturally makes a considerable degree of autonomy by learning control, but in a limited autonomy, teacher Themes can be used to help build relevant knowledge.

Secondly, the second classes are places of students to carry out self-study. Student use of multimedia equipment available to mimic familiar with all aspects of self-learning process, extending classroom learning processes and tasks, explore their own interests and strengths, develop relevant learning content. Meanwhile, a second classroom teachers' guide may be performed by a network platform or E-mail. Multimedia condition restricted schools, teachers can teach classes to set public mailbox to publish information, arranged learning task [5].

\section{Conclusion}

Self-learning is a new teaching concept, self-learning environment at home and abroad have considerable differences, therefore, we need to according to China's national conditions, step by step, to strengthen the functions of classroom teaching to achieve self-learning teaching objectives . Do not go to extremes and completely abandon the traditional teaching methods, not only to focus on training learning, but also to pay attention to the input and strengthening language knowledge.

\section{References}

[1] X.D.He, Research on a number of issues of domestic independent study, J. Foreign Language. 44 (2010) 146-147.

[2] H.B.Qi, The analysis of self-awareness of Chinese foreign language learners, J. Foreign Language Teaching. 18(2005) 55-57.

[3] M.Zheng, The origin and development of self-learning, J. Xi'an International University, 32(2012) 189-190.

[4] D.Q.Wang, The college English self-learning ability, J, Foreign Language, 4(2007) 38-40.

[5] D.W.Chuan, The positioning of foreign language teachers in independent study mode, J. Foreign Language, 9(2013) 142-150. 